\title{
Oropharyngeal Control of Hand-Mouth Coordination in Newborn Infants
}

\author{
Philippe Rochat, Elliott M. Blass, \\ and \\ Lisa B. Hoffmeyer \\ Johns Hopkins University
}

\begin{abstract}
This research identifies a coordinative structure of action that integrates hand and mouth activities within hours after birth. Infants in the supine position received 7 presentations of $12 \%$ sucrose solution. Differences in hand-mouth coordination relative to preceding and succeeding epochs of nonsucrose presentation were striking: $32 \%$ of the sucrose period was spent by infants with hands inside the mouth or in contact with it, and $18 \%$, for the same measures during periods of nonsucrose delivery. In addition the hand was brought to the mouth $50 \%$ more often during the sucrose period. These data provide evidence for oropharyngeal control over integration of gross motor patterns of hand movement as they relate to the mouth. A possible functional significance of these findings is discussed.
\end{abstract}

A central concern of students of developmental processes is an understanding of the coordination of separate motor activities of differing origins into a smoothly functioning, integrative unit. Interest in this issue spans the range from the development of neural processes (Bekoff, 1971; Fentress \& McCleod, 1986; Hamburger, 1973) to interlimb motor control (Bekoff 1971; Fentress, 1973; Thelen, Ridley-Johnson, \& Fisher, 1983) to development of cognitive and perceptual processes (Bushnell, 1981; Piaget, 1952) to ego development (Abraham, 1968).

The study of hand-mouth coordination is an obvious way to understand the general process of intermodal coordination in newborn human infants. This pattern of placing the hand in the mouth or its immediate surround is exercised during the confines of pregnancy (Humphrey, 1970) and during the early months of infancy. The significance of this pattern as a vehicle for obtaining information about the characteristics and affordances of objects in the environment is most apparent when infants, starting from about 4 months of age, systematically bring to the mouth objects that they grasp (Rochat, 1985). Hand-mouth coordination may occur concomitantly with, or be the precursor of, hand-eye coordination (Korner \& Kraemer, 1972; Piaget, 1952). Moreover, as is well known, the hand in the mouth can be pacifying.

This research was supported by Grant in Aid of Research HD 19278 from the National Institute of Child Health and Human Development, and Research Scientist Award MH 00524 from the National Institute of Mental Health to Elliott Blass. Support for Philippe Rochat was provided by the Swiss National Science Foundation (FNRS), Fellowship No. 81.082-0.83. We thank Tom Fillion for comments on an earlier draft.

Philippe Rochat is currently at the University of Massachusetts.

Correspondence concerning this article should be addressed to Elliott Blass, Department of Psychology, Johns Hopkins University, Charles and 34th Streets, Baltimore, Maryland 21218.
Despite the acknowledged importance of this coordinative system, remarkably few studies have been addressed to its development. This may reflect an acceptance of Piaget's interpretation that hand to mouth behavior is fortuitous before 6 weeks of age. In those studies that have investigated its occurrence, the incidence of hand-mouth contact in supine nonfeeding infants up to 5 days of age is impressive. For example, approximation of Korner's film analysis (Korner, Chuck, \& Dontchos, 1968) indicated that the hand was in contact with the mouth more than $20 \%$ of the time (Anneliese Korner, personal communication, June 1987).

During the collection of data on conditioning studies (Blass, Ganchrow, \& Steiner 1984; Blass \& Hoffmeyer, 1988), we observed that many infants brought a hand to their mouth and kept it there for long periods of time on delivery of sucrose solution. This observation prompted the present analysis, in which we report that sucrose delivered to the mouth gains control over hand-mouth contact and focuses the activity of the hand away from the face, body, and surround toward the oral and perioral region. We obtained the data presented in this report as part of a different study with a different purpose but analyzed retrospectively from the vantage of hand-mouth coordination.

\section{Method}

Subjects were 10 full-term normal newborns, 5 boys and 5 girls, with gestational ages between 38 and 43 weeks $(M=39.7)$ and postnatal ages ranging from 7 to 57 hours $(M=28.7)$. The 10 infants of the present study were randomly drawn from the larger population of the research for which they had been originally tested. Three of the subjects were bottle fed and 7 were breast fed between $20 \mathrm{~min}$ and $2 \mathrm{hr}$ before testing $(M=68.8 \mathrm{~min})$. The infants were tested while lying supine in their own bassinets in a quiet room of the nursery of Sinai Hospital in Baltimore, Maryland. The bassinets were inclined about $30^{\circ}$ to situate the baby en face with a video camera.

We filmed each infant for a total of 26 min divided into three phases. 
The first phase was a baseline observation of five 1-min trials. Each 1min trial started with $10 \mathrm{~s}$ of a sound, either psst or shh delivered twice per second. This was followed by a test phase of $14 \mathrm{~min}$ divided into seven trials, each of 2-min duration. After the $10 \mathrm{~s}$ of sound, $.20 \mathrm{ml}$ of a $12 \%$ sucrose solution was delivered via a sterile syringe into the neonate's mouth at the midline. The experimenter stood at the infant's left side. Finally, the test phase was followed by another baseline observation period of $7 \mathrm{~min}$.

We analyzed manual behavior relative to the mouth and face during baseline periods of observation in which no sucrose was administered and during test periods when sucrose was delivered once (for $10 \mathrm{~s}$ ) every 2 min.

Observers determined both the frequency and duration of hand touching either the face or the mouth area through continuous analysis of the video records. The observers analyzed the video records using a continuous viewing procedure, coding behavior in real time via a multichanneled polygraphic event recorder. Four channels of the event recorder were used and right- or left-hand contacts with either facial or mouth area were coded. While viewing the videotape, observers activated a particular channel of the event recorder by pushing a corresponding button at the onset of a manual contact with either the mouth area or the face area and releasing it when contact ended. On the basis of the polygraphic transcript of the videotapes. we added occurrence (frequency) of hand contacting either the face area or the mouth area as well as the duration of these contacts for each of the three experimental phases (two baseline periods and test). The mouth area was delimited by the periphery of the lips and included the inside of the mouth. The face area was broadly defined as the facial region, including head and neck but excluding the mouth. We calculated the interobserver reliability of two independent observers who coded 8 subjects on the frequency and duration of hand touching the mouth. Using Pearson's productmoment correlation test, we found interobserver reliability to be above .95 for the two measures at each of the three phases of the experiment.

\section{Results}

Infants brought their hands to their mouth more often and for longer periods of time during the sucrose phase. Specifically, the duration of hand-mouth contact almost doubled relative to baseline periods (Figure 1). We determined that the differences were statistically significant using analysis of variance, $F(2$, $9)=4.46, p<.03$. There was no significant effect of right versus left hand, nor was there a statistically significant interaction between hand and condition.

The frequency of hand-mouth contact also increased markedly. The ratio $F_{m} /\left(F_{m}+F_{f}\right)$, where $F_{m}$ represents frequency of hand to mouth and $F_{f}$ represents frequency of hand to face, revealed that infants brought their hands to their mouths more often during the sucrose phase of the experiment (Figure 2). This ratio, originally provided by Wolff (1966) and discussed by Korner and Kraemer (1972), captures movement of the hands to the mouth during sucrose stimulation and away again on sucrose termination.

The increased frequency and duration of hand-mouth contact during the test phase were not due simply to a global change of manual activity in the newborn: Figure 3 shows that there was a shift in hand location relative to the face and no significant change in global manual activity, $F(2,9)=0.29$, ns. Stated differently, the hand made contact with the mouth at the expense of the face and other contacts, which suggests a change in coordinated motor behavior precipitated by sucrose adminis-

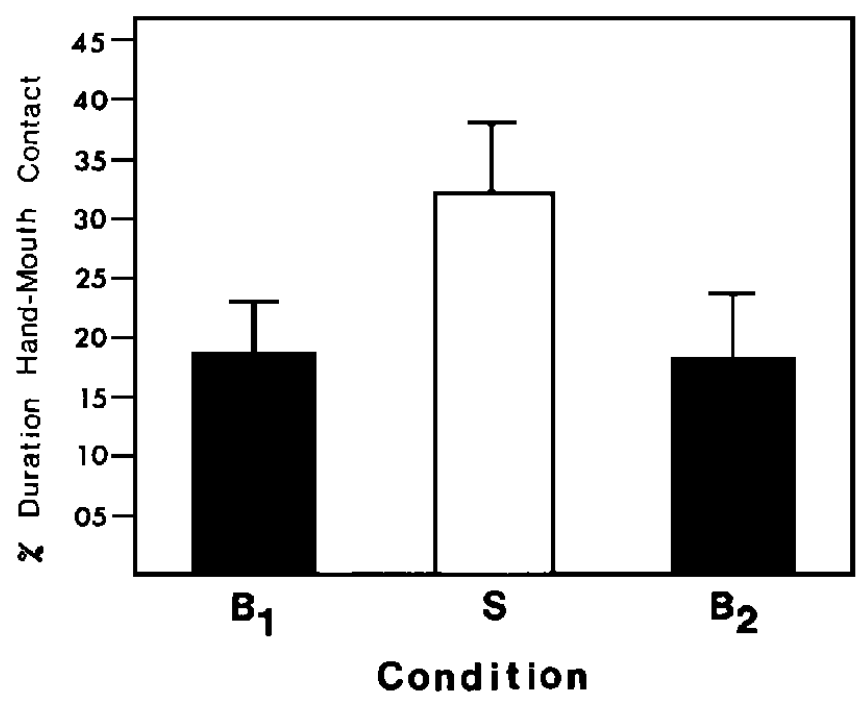

Figure I. Mean percent duration of hand-mouth contact during the first $\left(B_{1}\right)$ and second $\left(B_{2}\right)$ baseline observations when no sucrose was given to the infant and during the period in which sucrose (S) was given once every $2 \mathrm{~min}$.

tration. The increase in mouth contact cannot be attributed simply to a more active hand engaging different body parts with increased frequency.

\section{Discussion}

The results confirm previous observations of hand-mouth coordination within hours after birth (Butterworth, 1986; Korner \& Beason, 1972; Korner et al., 1968; Korner \& Kraemer, 1972). In general, our study indicates that certain hand-mouth contacts in neonates may be stimulus-dependent and facilitated by sucrose administration: Hands are brought more frequently to the mouth and the duration of manual contacts with the oral zone increases following sucrose stimulation. The phenomenon reported here consisted of shifting the pattern of hands contacting face and its surround to that of handmouth contact and active engagement.

Although hand and finger sucking are prominent at birth and have been commonly observed by scientists, pediatricians, and parents alike, heretofore, the behavior had been viewed as fortuitous (Piaget, 1952). That is, the infant lying on its side may have had its hand in close contact with its mouth, eliciting rooting and hand grasping by the mouth. In more formal observations of supine newborn infants (Kessen, Williams, \& Williams, 1961; Korner et al., 1968), hand-mouth contact was described as brief and not sustained. The present report demonstrates that this behavior can be both protracted and contracted under experimental control.

From the protraction of hand-mouth bebavior with sucrose and its contraction with sucrose withdrawal we infer an integrative system that can gain control over hand-to-mouth contact at birth. Bringing the hand to the mouth during the sucrose phase of the experiment may not simply reflect passive contact 


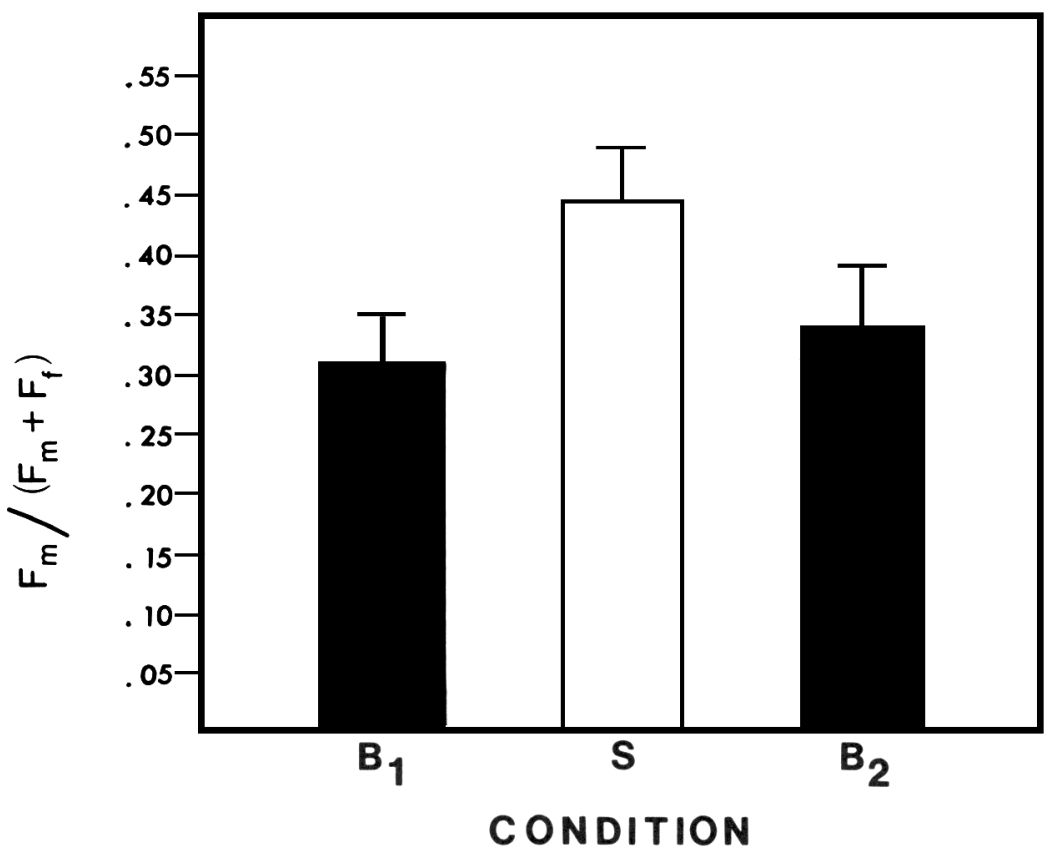

Figure 2. Mean ratio of the frequency with which the hand was brought to the mouth (Fm) relative to that in which it was brought to the mouth and face ( $\mathrm{Fm}+\mathrm{Ff})$ during the baseline and sucrose periods.

of the hand at the perioral (trigeminal) zone. Rather the system appears to be active, as inferred from the apparent smoothness of bringing the hand to the mouth and the occasional reaching of the mouth for the hand prior to contact.
The mechanism of this action has not yet been determined, but it may reflect the calming change of state caused by sucrose administration (we are currently assessing this possibility). Another possibility is that sucrose engages the suckling mecha-

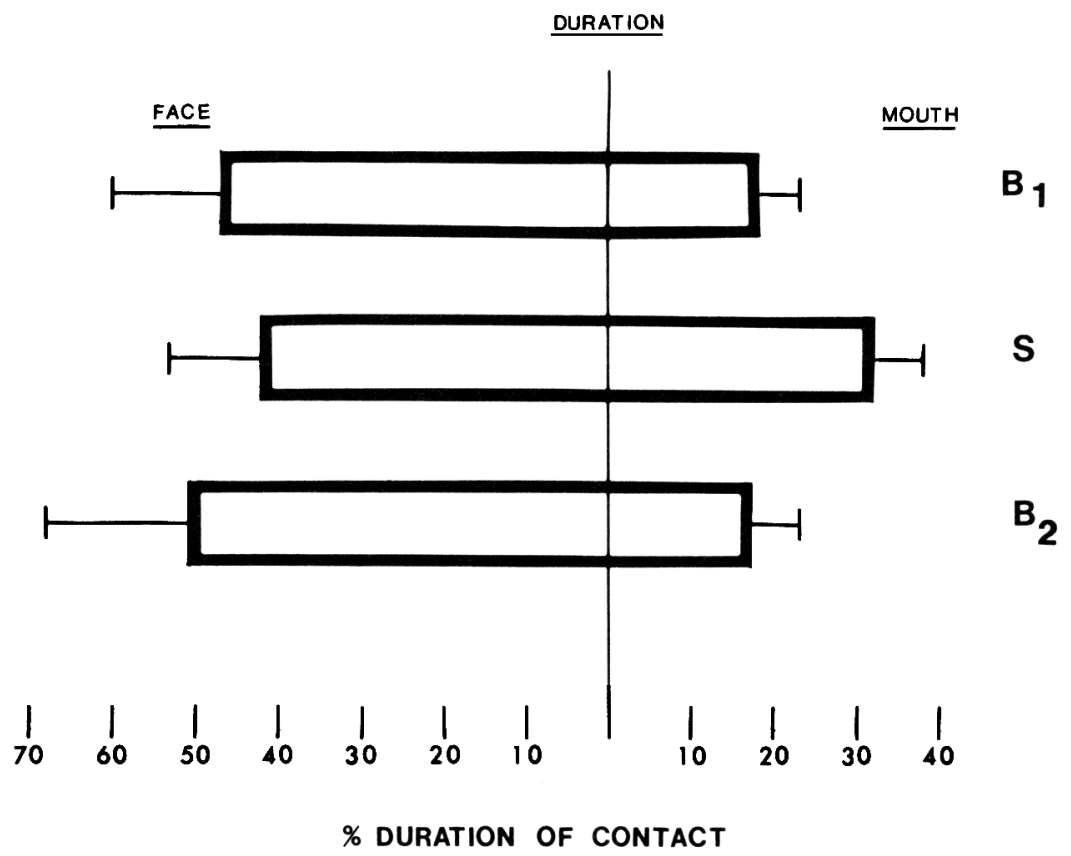

Figure 3. Mean percent duration of contact of hand to mouth or face during $B_{1}, S$, and $B_{2}$ periods. (The area of each rectangle represents the global manual activity concerning hand-mouth and hand-face contact.) 
nism, which not only entails oral activities but also integrates manual behavior. A prominent feature of suckling engagement is the placing of hands at the milk source by the infant. Under normal circumstances, the hands are stopped short of the mouth but will routinely enter the mouth on nursing termination by the mother (Hoffmeyer, 1987). In the present study, oral stimulation was of a short duration and movement of the hands to the mouth was essentially unimpaired.

The hand-to-mouth pattern in human neonates might correspond to a prefunctional feeding response that is distinct from, yet associated with, suckling. The different motor patterns between suckling and feeding may also reflect different internal controls such as gastric distention (Blass \& Teicher, 1980; Hall $\&$ Williams, 1983). Sucrose may have activated the feeding system. a situation that has the intrinsic feature of bringing the hand to the mouth as a precursor of self-feeding.

The interpretations of hand-mouth coordination in this study reflecting engagement of a suckling/feeding mechanism. at first, may seem to be at odds with the interpretation of Kessen et al. (1961) that hand-mouth coordination is independent of feeding. In fact, this study is not at odds with Kessen et al.. who reached their conclusion on the basis of no systematic change in hand-mouth activity during the first 5 postnatal days and did not systematically reflect time since last feeding. Their conclusion is valid to the extent that the suckling/feeding system was not actively engaged by an external stimulus. In the present study, the system was engaged. and. as indicated, hand-mouth contact may' have reflected that engagement.

A cautionary note concerning the limits of this interpretation deserves mention. We have not fully exhausted the classes of stimuli that will elicit hand-mouth coordination. We can state with confidence, however, that stimulation of the hand with fluid, light pressure, or with fabric did not cause it to come to the mouth. Other classes of stimulation are currently being explored.

Wolff's ( 1966) conclusion that hand-mouth coordination accurately reflects a change in general activity was not addressed in the current study because we did not measure general actisity. It is important, however, to note that increased hand-mouth activity in response to sucrose delivery did not reflect a general change in manual activity (as shown in Figure 3).

From the perspective of early perceptual and cognitive development, these data are consistent with the classic progression of integrated motor patterns that become available to novel sensory stimulation. In the classic developmental progression of sensory motor systems, motor patterns or subsystems (e.g., leg movements in birds) develop in advance and independent of sensory influences (Hamburger, 1973; Oppenheim \& Haverkamp. 1986). When the sensory sy stems become anatomically' and functionally available they then gain control ox'er the "corresponding" facet of the motor pattern. This general rule holds across different levels of the neuraxis. for different periods of development (Hamburger. 1973). and in a variety of birds and mammals (Bekoff. 1971), including human fetuses (Humphrey. 1970).

The present findings are similar to. yet somewhat different from, the classic progression-similar in that the integrated behavioral pattern has come under the control of a novel stimulus that engages motoric and motivational facets of the suckling/ feeding system (Blass et al., 1984; Blass \& Hoffmeyer, 1988). The hand-mouth coordinative system differs from this progression by the time of birth because it has already been influenced by the sensory feedback obtained in ulero at a time that the gustatory system is at least partially functional (Misteretta \& Bradley, 1986). It is exceedingly unlikely, however, that sucrose receptors have even received stimulation as they did in the present experiment. The present findings may approximate certain naturally occurring exchanges between infant and mother. To the extent that sucrose administration engages the suckling system we are provided with the opportunity of exploring the significance of infants' bringing their hands toward the mouth during suckling from either breast or bottle and, especially. the bringing of hands to mouth at the termination of the suckling bout.

\section{References}

Abraham. K. (1968). The influence of oral eroticism on character formation. In Sclected papers on psichoanalysis (6th ed., pp. 393-406). New Yórk: Basic Books.

Bekoff. A. (1971). Ontogeny of leg motor output in the chick embryo: A neural analysis. Brain Research. 106. 271-291.

Blass, E. M.. Ganchrou, J. R.. \& Steiner. J. E. ( 1984). Classical conditioning in newborn humans 2-48 hours of age. Infam Behavior and Development. - 223-235.

Blass, E. M.. \& Hoffmeyer. L. (1988). Selective auditory classical conditioning in new born human iniants Manuscript submitted for publication.

Blass. E. M., \& Teicher. M. H. (1980). Suckling. Science. 210, 15-22.

Bushnell, E. W. (1981). The ontogeny of intermodal relations: Vision and touch in infancy. In R. W. Walk \& H. L. Pick (Eds.), Intersensory' perception and sensory integration (pp. 5-36). New York: Plenum.

Butterworth. G. (1986, April). Hand to mouth activity in the newborn hab!: Evidence lor innate intentionality?'Paper presented at the International Conference on Infant Studies. Los Angeles. CA.

Fentress, J. C. (1973). Development of grooming in mice with amputated forelimbs. Science, 179, 704-705.

Fentress. J. C., \& McLeod. P. J. ( 1986). Motor patterns in development. In E. M. Blass (Ed.), Hundhook of behaworal neurobiology: Iol. 8. Developinemal psichobiology and developmental neurobiolog. (pp. 35-98). New York: Plenum.

Hall. W. G.. \& W'illiams, C. L. (1983). Suckling isn't feeding. or is it? A search for developmental continuities. In J. S. Rosenblatt (Ed.), Adrances in the study of behavior (Vol. 13, pp. 219-254). New York: Academic Press.

Hamburger, V. (1973). Anatomical and phy siological basis of embryonic motility in birds and mammals. In G. Gottlieb (Ed.), Studies in the development of hehavior and the nerious system: Vol. I. Behartoral embryvlogy'(pp. 52-76). New York: Academic Press.

Hoffmeyer, L. B. (1987). [Feeding patterns and neurobehavioral development in infants of diabetic mothers] Unpublished observations.

Humphrey. T. (1970). The development of human fetal activity and its relation to postnatal behavior. In H. W. Reese \& L. Lipsitt (Eds.), Adrances in child development and behavior (Vol. 5.. pp. 1-57). New York: Academic Press.

Kessen. W.. Williams, E. J.. \& William. J. P. (1961). Selection and test of response measures in the study of the human newborn. Child $D e$ relopment, 32, 7-24.

Korner, A. F.. \& Beason. L. M. (1972). Association of two congenitally 
organized behavior patterns in the newborn: Hand-mouth coordination and looking. Perceptual and Motor Skills, 35, 115-118.

Korner, A. F., Chuck, B., \& Dontchos, S. (1968). Organismic determinants of spontaneous oral behavior in neonates. Child Development. 39, 1145-1157.

Korner, A. F., \& Kraemer, H. C. (1972). Individual differences in spontaneous oral behavior in neonates. In James F. Bosma (Ed.), Third Symposium on Oral Sensation and Perception (pp. 335-346). Bethesda, MD: U.S. Department of Health. Education and Welfare.

Misteretta. C., \& Bradley, R. (1986). Development of the sense of taste. In E. M. Blass (Ed.), Handbook of behavioral neurobiology: Vol. 8. Developmental psychobiology' and developmental neurobiology' (pp. 205-236). New York: Plenum.

Oppenheim, R. W., \& Haverkamp, L. (1986). Early development of behavior and the nervous system: An embryological perspective. In $\mathrm{E}$. M. Blass(Ed.), Handbook of behavioral neurobiology: Vol. 8. Develop- mental psychobiolog! and developmental neurobiology (pp. 1-34). New York: Plenum.

Piaget, J. (1952). The origin of intelligence in children. New York: Norton.

Rochat, P. (1985. July). From hands to mouth and eye: Development of an intermodal exploration by young infants. Paper presented at the 8th Biennial Meetings of the International Society for the Study of Behavioral Development, Tours, France.

Thelen, E., Ridley-Johnson, R., \& Fisher, D. M. (1983). Shifting patterns of bilateral coordination and lateral dominance in the leg movements of young infants. Developmental Psychobiology; 16, 29-46.

Wolff. P. H. (1966). The causes, controls, and organization of behavior in the neonate. Psychological Issues, 5 (1, Monograph 17).

Received July 9, 1987

Revision received October 21, 1987

Accepted November 25, 1987

\section{Call for Nominations for Behavioral Neuroscience}

The Publications and Communications Board has opened nominations for the editorship of Behavioral Neuroscience for the years 1990-1995. Richard F. Thompson is the incumbent editor. Candidates must be members of APA and should be available to start receiving manuscripts in early 1989 to prepare for issues published in 1990 . Please note that the P\&C Board encourages more participation by women and ethnic minority men and women in the publication process and would particularly welcome such nominees. Submit nominations no later than August 1, 1988 to

$$
\begin{gathered}
\text { Martha Storandt } \\
\text { Department of Psychology } \\
\text { Washington University } \\
\text { St. Louis, Missouri 63130 }
\end{gathered}
$$

Other members of the search committee are Byron Campbell, Mortimer Mishkin, Mark Rosenzweig, and Shepard Siegel. 